Article

\title{
Spatiotemporal Variance Assessment of Urban Rainstorm Waterlogging Affected by Impervious Surface Expansion: A Case Study of Guangzhou, China
}

\author{
Huafei Yu®, Yaolong Zhao *, Yingchun Fu * and Le Li \\ School of Geography, South China Normal University, Guangzhou 510631, China; \\ yuhuafei@m.scnu.edu.cn (H.Y.); lile.joanna@gmail.com (L.L.) \\ * Correspondence: zhaoyaolong@m.scnu.edu.cn (Y.Z.); fuyc@m.scnu.edu.cn (Y.F.)
}

Received: 17 September 2018; Accepted: 15 October 2018; Published: 18 October 2018

check for updates

\begin{abstract}
Urban rainstorm waterlogging has become a typical "city disease" in China. It can result in a huge loss of social economy and personal property, accordingly hindering the sustainable development of a city. Impervious surface expansion, especially the irregular spatial pattern of impervious surfaces, derived from rapid urbanization processes has been proven to be one of the main influential factors behind urban waterlogging. Therefore, optimizing the spatial pattern of impervious surfaces through urban renewal is an effective channel through which to attenuate urban waterlogging risk for developed urban areas. However, the most important step for the optimization of the spatial pattern of impervious surfaces is to understand the mechanism of the impact of urbanization processes, especially the spatiotemporal pattern of impervious surfaces, on urban waterlogging. This research aims to elucidate the mechanism of urbanization's impact on waterlogging by analysing the spatiotemporal characteristics and variance of urban waterlogging affected by urban impervious surfaces in a case study of Guangzhou in China. First, the study area was divided into runoff plots by means of the hydrologic analysis method, based on which the analysis of spatiotemporal variance was carried out. Then, due to the heterogeneity of urban impervious surface effects on waterlogging, a geographically weighted regression (GWR) model was utilized to assess the spatiotemporal variance of the impact of impervious surface expansion on urban rainstorm waterlogging during the period from the 1990s to the 2010s. The results reveal that urban rainstorm waterlogging significantly expanded in a dense and circular layer surrounding the city centre, similar to the impervious surface expansion affected by urbanization policies. Taking the urban runoff plot as the research unit, GWR has achieved a good modelling effect for urban storm waterlogging. The results show that the impervious surfaces in the runoff plots of the southeastern part of Yuexiu, the southern part of Tianhe and the western part of Haizhu, which have experienced major urban engineering construction, have the strongest correlation with urban rainstorm waterlogging. However, for different runoff plots, the impact of impervious surfaces on urban waterlogging is quite different, as there exist other influence factors in the various runoff plots, although the impervious surface is one of the main factors. This result means that urban renewal strategy to optimize the spatial pattern of impervious surfaces for urban rainstorm waterlogging prevention and control should be different for different runoff plots. The results of the GWR model analysis can provide useful information for urban renewal strategy-making.
\end{abstract}

Keywords: urban rainstorm waterlogging; impervious surface; geographically weighted regression; spatiotemporal variance; Guangzhou 


\section{Introduction}

Urban rainstorm waterlogging refers to the phenomenon of a stagnant water disaster in an urban area due to heavy rainfall or continuous precipitation, resulting in the collapse of social engineering systems and the loss of social economy [1,2]. In recent years, urban rainstorm waterlogging has occurred frequently around the world, especially in developing countries such as China. It has become one of the major "city diseases" in the world, in addition to population congestion, traffic congestion, environmental pollution, and so on [3]. According to the statistical results for 350 cities in China from the Ministry of Housing and Urban-Rural Development, $62 \%$ of these cities have suffered from urban rainstorm waterlogging, with 137 cities suffering more than three times, including Beijing, Shanghai, Nanjing, Tianjin, and Guangzhou [4-9]. The urban rainstorm waterlogging situation is especially serious in contiguous urban agglomeration areas such as the Pearl River Delta in China [10]. Guangzhou, as the capital of Guangdong Province, located in the Pearl River Delta of South China, is the most representative city suffering from serious urban rainstorm waterlogging. Eliminating or attenuating urban rainstorm waterlogging risk has become an urgent mission for the local governments of such cities.

Mounting studies have indicated that the key influence factors in the frequent occurrence of urban rainstorm waterlogging can be summarized into three types. The first factor is the extreme weather caused by global climate change [11,12]. Extreme weather always causes frequent, high-intensity local rainfall [11,13]. Urban drainage design and projects in some cities of developing countries are substandard, which makes heavy rain difficult to resist with long recurrence [14-16]. Therefore, urban drainage design and project standards form the second factor. The third factor is impervious surfaces. The rapid urbanization process in some regions or countries leads to the rapid growth of impervious surface areas in cities. Impervious surfaces reduce the infiltration capacity of the urban surface to rainwater, shortens the time for surface runoff, and then aggravates the "Rain Island Effect" [17]. Corresponding to the three main factors, urban waterlogging prevention and control methods can be summarized into three categories. The first method is to reduce the occurrence of extreme rainfall. However, in the current global warming environment, reducing extreme rainfall is difficult to achieve [18]. The second is to improve the standard of urban drainage project planning and design for the rainfall recurrence period. Due to urban traffic disruption and the huge maintenance cost of municipal facilities, schemes to implement urban pipeline network renewal are difficult to carry out [19-22]. The third method is to increase rainwater infiltration into the soil or vegetation in urban areas to reduce surface runoff, which is always mentioned by relevant researchers in the study of urban waterlogging prevention and control around the world [17,23-27]. LID (Low Impact Development) is the most commonly used method for increasing rainwater infiltration [28-31]. Cities with such functions for rainwater infiltration are called "sponge cities" in China [32]. Compared with the former two methods, the third method, increasing rainwater infiltration into soil or vegetation in the urban area, not only achieves reduction of runoff sources but can also be used sustainably with a lower cost [26,33-35]. Therefore, this method should be the most suitable for urban waterlogging prevention in developing countries such as China.

Increasing rainwater infiltration means that the current spatial pattern of the urban area should be adjusted. This adjustment is a big project for a city if the project is carried out solely for urban waterlogging prevention. Nevertheless, the adjustment of an urban area's spatial pattern can be carried out accompanied by urban renewal. Urban renewal is a planned renovation of the developed urban area in the world at this new stage of development [36,37]. Presently, the urbanization process in China has shifted from the increase in urban area size to the improvement of urban quality through urban renewal [38-41]. How to increase rainwater infiltration by adjusting the spatial pattern of the urban area through urban renewal is also an important mission of urban renewal and will be a challenge in the field of urban planning.

Tang et al. (2018) have shown that impervious surfaces are more important than other factors among urban factors affecting rainstorm waterlogging [3]. Impervious area is a key index of the urban 
environment [42-45]. Therefore, it is more commonly targeted to explore the effect of impervious surfaces on rainfall runoff. Some researchers have authenticated that the area of the impervious surface has great influence on rainfall runoff. Therefore, the increase of impervious surface area has a significant effect on urban water circulation, which is the main factor behind urban rainstorm waterlogging $[17,46,47]$. For example, Urbonas et al. (2005) plotted the correlation between the urban storm runoff coefficient and urban impervious surface area ratio, indicating that the increase in impervious characteristics of underlying urban surfaces resulted in the rapid increase of urban runoff coefficient. Brun et al. [48]. (2000) noted that if the surface runoff of urban impervious surfaces increases by 0.1 to 1 times, the surface runoff will increase by $2-5$ times $[49,50]$. Rose et al. $(2001)$ found that the peak of rainfall runoff in urbanized areas was more than $30 \%$ higher than that in natural basins [51]. The above studies pay more attention to the effect of impervious surface area. In fact, impervious surface area stands in for the built-up area of an existing city in much research. Therefore, for a developed city, it is not realistic to decrease the impervious surface area through urban renewal. Researchers have found that, apart from the area, the spatial pattern of impervious surfaces also has a great influence on urban rainfall runoff [52]. For example, Zheng et al. (1999) set up four spatial pattern scenarios in the North American city of Ancaster, and the results show that the spatial pattern of urban land use has a significant impact on surface rainfall runoff [53]. Poff et al. (2006) found that different urban land use distributions have an important influence on rainfall runoff [54]. Mejia and Moglen (2009) pointed out that the hydrological model is very sensitive to the location of the impervious surface [55]. That is, different spatial patterns of the same total impervious surface area will significantly impact rainfall runoff [56]. This finding means that urban renewal should formulate different planning policies for different regions of impervious surfaces. Therefore, understanding the spatiotemporal variance of impervious surfaces on urban rainstorm waterlogging can help urban renewal planning in the selection of a region for urban rainstorm waterlogging prevention and control. Adjustment of the impervious surface should thus be the main object of urban renewal planning for urban rainstorm waterlogging prevention and control. Accordingly, understanding the mechanism of the impact of impervious surface areas on urban rainstorm waterlogging is a vital mission for urban renewal planning.

Although the viewpoint that the spatial pattern of impervious surfaces can affect rainfall runoff has been recognized, studies have always been carried out from a global spatial perspective. According to Tobler's (1970) first law of geography, the assumption that research units are independent and homogeneous with one another is difficult to establish [57]. The fact that there is spatial variance between the occurrence of urban rainstorm waterlogging and the expansion of impervious surface is affirmatory [58,59]. The local differences in spatial variance are easily ignored from a global spatial perspective. Therefore, the influence of the spatial pattern of impervious surfaces on urban rainstorm waterlogging needs to be further explained. It is helpful to explore the local differences in urban rainstorm waterlogging from a local perspective. Comparing the effects of the expansion of impervious surfaces in different periods on urban rainstorm waterlogging can reveal the differences over time. At present, there are still insufficient studies on spatiotemporal variance in the effects of impervious surface expansion on urban rainstorm waterlogging. This paper explored the spatiotemporal characteristics of impervious surfaces and urban rainstorm waterlogging in a case study of Guangzhou and revealed the spatiotemporal relationship between urban rainstorm waterlogging and impervious surface expansion from the local spatial perspective during the period from 1990 to 2012. The results will provide a theoretical basis for urban renewal planning for urban rainstorm waterlogging prevention and control.

\section{Study Area}

The study area is located in the centre of the city of Guangzhou in China, that is, downtown Guangzhou, including Tianhe, Yuexiu, Haizhu, Baiyun, Huangpu, Liwan, and Luogang districts (Figure 1). Guangzhou, a city with a population of over 14 million people [60], is the capital, political, economic, technological, educational, and cultural centre of Guangdong Province in China. According 
to the statistics, the Gross Domestic Product (GDP) in Guangzhou reached 2.00 trillion yuan in 2017, third after Beijing and Shanghai [61]. Guangzhou is located between longitude $112^{\circ} 57^{\prime}$ and $114^{\circ} 3^{\prime} \mathrm{E}$ and latitude $22^{\circ} 26^{\prime}$ and $23^{\circ} 56^{\prime} \mathrm{N}$, near the South China Sea, which is the junction of Xijiang, Beijiang, and Dongjiang rivers. This area has a maritime subtropical monsoon climate with high annual precipitation and heavy rain [11]. Since the well-known "open-door" policy and economic reform were adopted in China in 1978, urban rainstorm waterlogging in Guangzhou has become increasingly serious, causing great economic loss [8]. According to the statistics, from the 1980s to 2010, the number of urban rainstorm waterlogging events in urban areas increased from 7 to 113, a rate of nearly 16 times [62]. The waterlogging affected area has spread from Yuexiu to surrounding areas such as Tianhe, Haizhu, and Baiyun. Just in 2010, there were four severe risks of waterlogging in the downtown Guangzhou area. In addition to the climatic factors, the risk for waterlogging also includes the inadequate design of the urban pipe network and the unreasonable transformation of urban terrain caused by urbanization $[6,14,25]$. It is obvious that the frequent occurrence of urban rainstorm waterlogging in Guangzhou is also closely related to urban topography reconstruction.

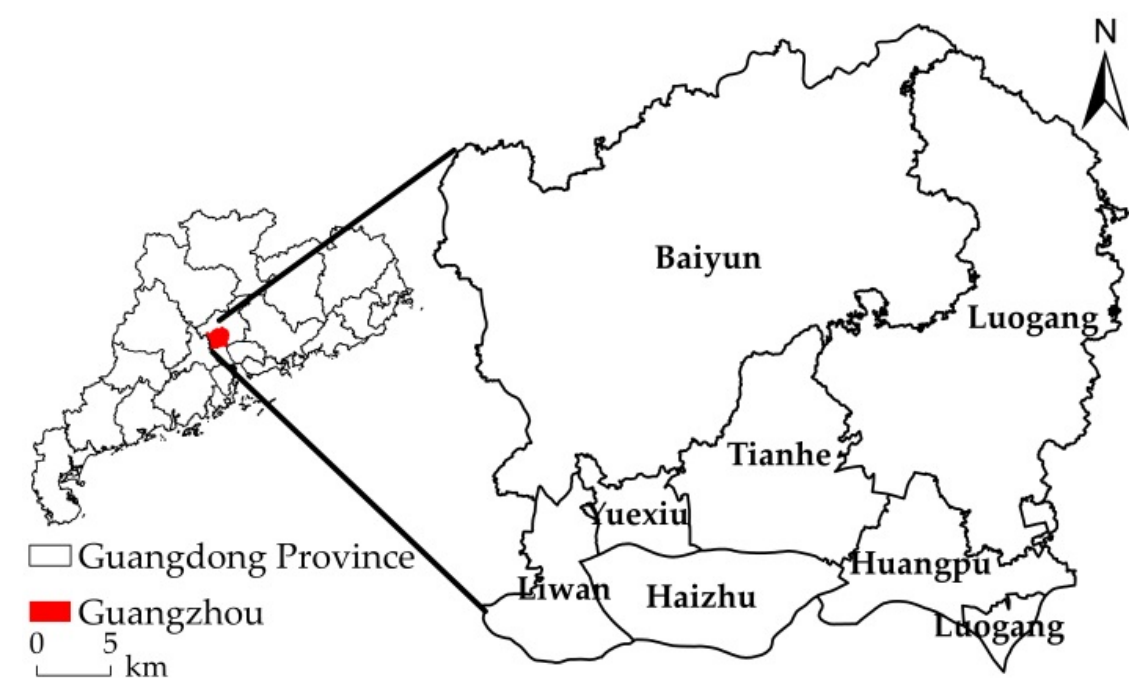

Figure 1. Study area.

As the frontier of China's reform and development, Guangzhou has experienced a rapid urban growth process since 1978 and now faces the limitation of land that can be transformed into built-up area. Since the Ministry of Land and Resources signed a cooperation agreement with the Guangdong Province government in 2008 to jointly build a pilot demonstration province to achieve intensive land use, the province has carried out demonstration work on the reconstruction of the urban area. Since that time, Guangdong Province has played an important role in urban renewal. In December 2014, the first Urban Renewal Bureau in China was set up in Guangzhou, responsible for updating the detailed planning of urban renewal so as to also solve "city diseases" such as urban rainstorm waterlogging using modern information technology and intelligence. Therefore, the city of Guangzhou is a typical area for this study. Research results can provide useful information for other cities.

\section{Data and Methods}

\subsection{Data}

Urban waterlogging events were not taken seriously by the government for many years, as there were a low number of urban waterlogging events at that time. Due to the lack of a standard with which to measure the degree of severity of urban rainstorm waterlogging, waterlogging data recorded by the government cannot generally cover all urban rainstorm waterlogging events. Some events that caused inconvenience in social life and traffic and seriously affected the lives of residents and property 
safety were recorded by print media due to their significant impact and the widespread concern they caused in the community. Therefore, data on this kind of serious urban rainstorm waterlogging event was also collected in addition to the historical records provided by the Water Supplies Bureau, the greater rainstorm and disaster situation management bureau in downtown Guangzhou after the reform and opening up (1983-2013). Some print media, such as the Guangzhou Daily newspaper and other media materials from the 1980s to 2010s, were collected to look for information on urban rainstorm waterlogging. Print media always records the address of these events. ArcGIS software and Google Earth were utilized for visual identification of these waterlogging events. These events were handled as "points" for most waterlogging events, with each event in these print media recorded as a point. If the location is a "point," such as the intersection of two roads, the entrance of the housing estate, concrete building, and so on, it is represented by a dot. If the record is a road section, according to the relevant region recorded by the public news and related waterlogging control record, its centre of mass is described as the event point, in accordance with the practices recommended by Huang et al. (2018) and Zhang et al. (2018) [56,63], due to the difficulty of corresponding to the specific location. Each data point represents an urban rainstorm waterlogging incident.

In addition, this study also collected remote sensing image data regarding downtown Guangzhou from Landsat 7 ETM with $30 \mathrm{~m}$ resolution from October to November 2010, using high-resolution images from 2000, 2008, and 2010 to achieve sampling and classification verification.

To classify urban runoff plots as research units, this study uses DEM $(5 \mathrm{~m})$ as the basic data. All data information is shown in Table 1.

Table 1. Metadata information.

\begin{tabular}{cccc}
\hline Data & Format & Time & Source \\
\hline 1:4 Million administrative divisions & Esri shape file & 2005 & National Geomatics Center of China \\
\hline \multirow{2}{*}{ Landsat remote-sensing image } & Img & $1990-11-03$ & USGS \\
& & $2099-11-15$ & \\
& & $2000-10-28$ & \multirow{2}{*}{ Google Earth aerial photo } \\
High-resolution remote sensing image & Jpeg & 2008 & \\
& & 2010 & LPangzhou Water Authority, Guangzhou Daily \\
\hline Waterlogging information & Text & $1980-2012$ & LAC \\
\hline Topographic data & Img & 2009 &
\end{tabular}

\subsection{Spatiotemporal Variance Analysis Method}

The integrated framework of this paper is shown in Figure 2. First, the urban runoff plot was extracted as the research unit, and the kernel density of urban rainstorm waterlogging and impervious surfaces was extracted to the urban runoff plot. Then, spatiotemporal analysis of urban rainstorm waterlogging was carried out, and local spatial autocorrelation analysis was conducted with impervious surface density. Then, the spatiotemporal changes of impervious surfaces were analysed by means of a land transfer matrix and barycentre migration. Finally, GWR was used to explore the relation between urban rainstorm waterlogging and impervious surfaces. The detailed steps of the main methods are shown below.

(1) Urban Runoff Plot Division

Urban rainstorm waterlogging happens when rainwater is not balanced in the catchment area in which the waterlogging point is located. It is difficult to cure this "city disease" from only the viewpoint of the waterlogging point. Therefore, the study of urban storm waterlogging should be carried out from the perspective of the catchment area and should fundamentally analyse the relationship between the waterlogging point and the catchment area. Simultaneously, there is a relationship between urban rainstorm waterlogging disaster areas and urban planning units, that is, the greenbelt rate in detailed control planning is directly related to the urban water permeability capacity. In the field of urban hydrological ecology study, scholars have put forward the "watershed-land" unit model [64]. 
This study combines the urban watershed division technique with the detailed control planning area index to divide the urban runoff plot, realizing the combination of hydrological and ecological units with traditional planning units. Such a combination makes the urban runoff plot more natural and ecologically significant and simultaneously considers the urban-rural planning significance.

In the urban water environment system, the division of urban runoff communities follows the principle of large to small [65]. At the macro level, the main river network cuts across the urban area to form a number of independent waterlogging blocks, while the terrain features in each block determine the direction of water flow [66]. Guangzhou is located in the lower reaches of the Pearl River estuary, and the Pearl River cuts into the downtown area. Visual interpretation of high-resolution remote sensing images with 5-m DEM in Guangzhou allows for the extraction of the main drainage channels in the central area, forming a picture of the first-level drainage system (Figure 3). Finally, using the $5 \mathrm{~m}$ DEM data, the D8 algorithm is used to divide the catchment area of each level of drainage area (Figure 3). The catchment area is limited by the threshold value extracted by the control runoff network to meet the area requirement of the urban planning control unit. According to the size of the detailed control planning unit in Guangzhou, $0.2-0.5 \mathrm{~km}^{2}$ in the old main urban areas, and $0.8-1.5 \mathrm{~km}^{2}$ in the new urban area [67], the limited range of the catchment area is set to $0.2-1.5 \mathrm{~km}^{2}$. The above process is completed in the ArcGIS 10.2 hydrological analysis module. In the end, 600 urban runoff plots were divided into the research units, and the average waterlogging density and the impervious surface density of each runoff plot were calculated, respectively. The impervious surface density in this study is the ratio of the area of construction land and the area of runoff plots [9]. The impervious surface of this study mainly includes urban construction land with impermeable characteristics such as residences, transportation, and public facilities.

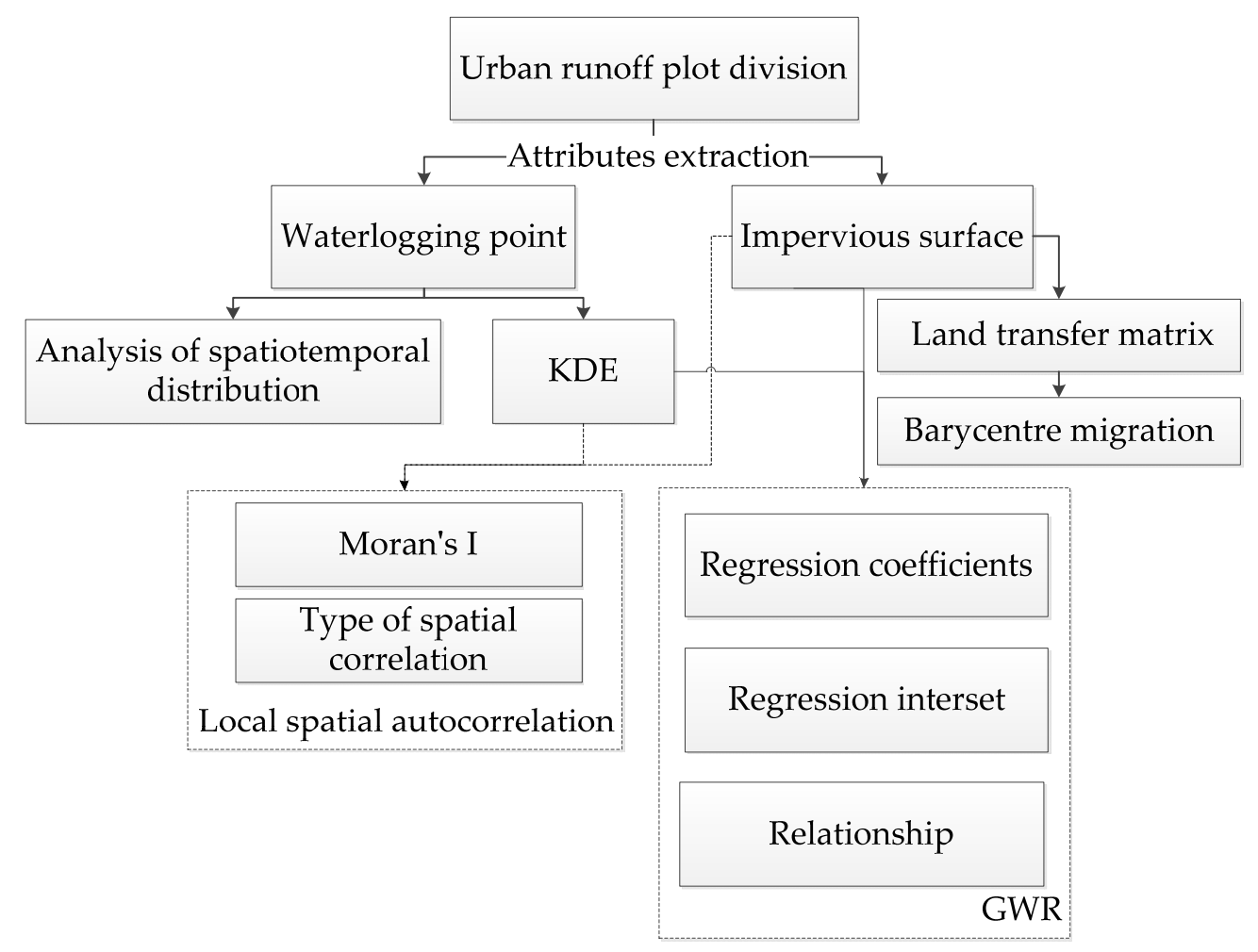

Figure 2. Integrated framework. 


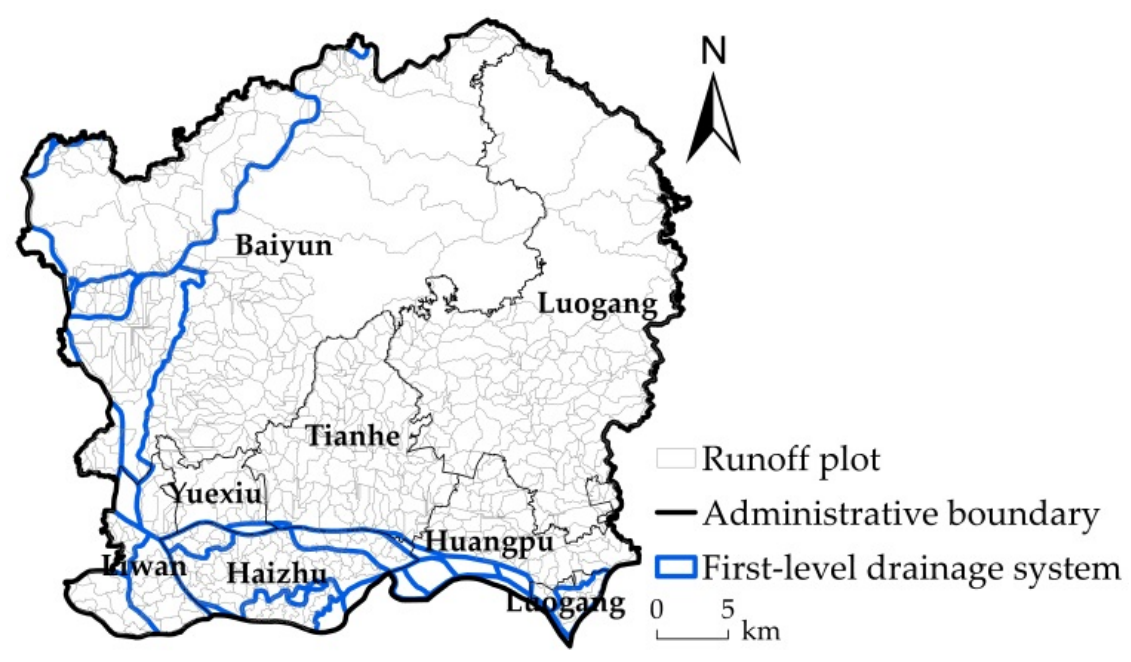

Figure 3. Watershed division in the study area.

(2) Kernel Density Estimation

Because the waterlogging events were handled as points, it is difficult to directly express the waterlogging situation of the neighbourhood. Therefore, Kernel Density Estimation (KDE) is used to obtain the degree of urban rainstorm waterlogging of these neighbourhood areas. KDE is an algorithm for nonparametric estimation, which is often used to compute the density of randomly distributed geographical objects [68]. The aim is to construct a smooth surface that represents the density of the point group. The algorithm is operated by setting the search scope (window). The weight of each grid unit is given from the central grid of the window outwards, according to the principle of anti-distance weight. Then, the kernel density value of the central grid is given as the sum of the product of all kernel density values and weights in the window. The Rosenblatt-Parzen estimation method is the most commonly used KDE and has been applied stably in various fields. Therefore, it is used in this paper to obtain the rainstorm waterlogging situation in various runoff plots.

$$
f_{n}(X)=\frac{1}{n h} \sum_{i=1}^{n} K\left(\frac{\Delta d}{h}\right)(i=1,2, \ldots, n)
$$

where $n$ is the number of event points in the window, $h$ bandwidth, $K$ the kernel function, and $\Delta d$ is the distance from the central grid in the window to the event point grid. In KDE, bandwidth is an important parameter. If the bandwidth is too large, the point density surface will become too smooth to cover the density structure of the point pattern, while a bandwidth that is too small will make the point density distribution change very abrupt [69]. Therefore, the optimal bandwidth of 1464 is determined by repeatedly setting the bandwidth and comparing the smoothness of the point density surface. The kernel function is a quadratic kernel function.

$$
K(X)=\left\{\begin{array}{cc}
\frac{3}{4}\left(1-X^{2}\right), & X \in[0,1] \\
0, & \text { otherwise }
\end{array}\right.
$$

(3) Local Spatial Autocorrelation

Because the waterlogging points are concentrated mainly in the Yuexiu, Tianhe, Haizhu, and Liwan districts, it is preliminarily decided that the occurrence has a certain dependence on space. We try to understand the dependence of urban storm waterlogging on space and to find its spreading characteristics by visualizing the spatial agglomeration degree of urban rainstorm waterlogging. In this study, the local spatial autocorrelation method is used to reflect the similarity and 
correlation of topographic factors among various research units and to visualize the spatial pattern of local differences [70,71]. The calculation method is as follows.

$$
\mathrm{I}_{i}=\frac{\mathrm{y}_{i}-\overline{\mathrm{y}}}{\mathrm{s}^{2}} \sum_{\mathrm{j}=1}^{\mathrm{n}} \mathrm{w}_{i j}\left(\mathrm{y}_{i}-\overline{\mathrm{y}}\right)
$$

where $I_{i}$ represents Moran's $I$ index of the research unit $i$ and $s^{2}$ is the discrete variance of $\mathrm{y}_{i} \cdot \overline{\mathrm{y}}$ is the mean the value $\mathrm{y} . \mathrm{w}_{i j}$ is the element of the weight matrix $\mathrm{w}$, indicating the spatial weight of the research unit $i$ and the research unit $j$, which is adjacent to the weight of 1 ; otherwise, it is 0 . The adjacent relation is the Queen type, that is, the grids are adjacent to each other as long as there is a common boundary or vertex [72].

The z-test value was used to determine whether the adjacent areas in the study area had similarity (spatial positive correlation), dissimilarity (spatial negative correlation), or mutual independence (random distribution) in the characteristic attribute [68]. The formula is as follows.

$$
\mathrm{Z}=\frac{I-E(I)}{\sqrt{\operatorname{Var}(\mathrm{I})}}
$$

where $E(I)$ represents the mathematical expectation of Moran's $I$ index under the hypothesis of spatial stochastic distribution and the $\operatorname{Var}(\mathrm{I})$ is the variation coefficient. It is stipulated that when $\mathrm{Z}$ is greater than 1.65, there is a positive spatial correlation, that is, a high-high concentration or a low-low concentration. When $\mathrm{Z}$ is less than -1.65 , there is a negative spatial correlation, namely, a high-low concentration or a low-high concentration [72,73]. In this study, we illustrate the clustering types and differences of local space with a LISA clustering diagram.

(4) Geographically Weighted Regression (GWR)

The relationship between impervious surfaces and rainfall runoff is studied from the global spatial perspective. Therefore, the local differences of the effects of impervious surfaces on urban rainstorm runoff are always neglected. In this study, we hope to explore the spatiotemporal variance between urban rainstorm waterlogging and impervious surface expansion from the perspective of local space. GWR is a modelling technique that can effectively deal with the geographical spatial variance phenomenon [74], which is often used to describe spatial variance that explains the effect of independent variables on dependent variables [75]. GWR is better than the traditional regression models based on homogeneous space in the study of spatial variance, such as the spatial expansion model [76]. In the face of spatial data as independent variables and independent variables that have spatial autocorrelation parameter estimation problems, the assumption that traditional regression model (OLS model) residuals are randomly distributed will not be established. Therefore, OLS of "average" or "global" regression will no longer apply [77]. GWR can make up for the disadvantage of OLS without considering the non-stationary spatial information, and the spatial position information is returned to the parameters, thereby realizing the local parameter estimation [78]. This model has been used in health geography, commercial geography, population geography, and other fields [79-81]. GWR has been applied less often in the field of urban rainstorm waterlogging. Therefore, it is of significance to study the spatiotemporal differentiation of the influence of impervious surface expansion on urban storm waterlogging. The calculation formula is as follows.

$$
y_{i}=\beta_{i 0}+\sum_{k=1}^{m} \beta_{i k} x_{i k}+\varepsilon_{i} \quad(i=1,2,3, \ldots, n)
$$

where $y_{i}$ represents the dependent variable of the research unit $i$. The intercept of the research unit $i$ is denoted by $\beta_{i 0}$. The regression coefficient of the $k$ explanatory variable in the research unit $i$ is represented by the $\beta_{i k} . x_{i k}$ represents the $k$ th explanatory variable of the research unit $i . \varepsilon_{i}$ represents the random error of the research unit $i$. The spatial correlation of model residuals is judged by the Z-test 
value, and the model can be trusted when the residual is randomly distributed. Spatial weighting is the key to GWR, and its function is divided mainly into fixed bandwidth and adaptive weight functions. Because of the difference in spatial density of runoff plots, if the weighted function of fixed bandwidth is chosen, an excessive number of research units will be involved in regression in the research unit-dense area, while areas sparse in research units will make the number of research units participating in regression insufficient, which will lead to too large a deviation of regression parameters. Therefore, the adaptive weight function is adopted in this study. The formula is as follows.

$$
w_{i j}= \begin{cases}1, & j \in k \\ 0, & j \notin k\end{cases}
$$

where $k$ is the number of adjacent elements that are set. In this study, the optimal number of adjacent elements is set according to the minimum AICC principle proposed by Fotheringham.

\section{Result}

\subsection{Spatiotemporal Evolution and Autocorrelation Analysis of Urban Rainstorm Waterlogging}

The spatiotemporal distribution of rainstorm waterlogging points in the study area is shown in Figure 4 . These waterlogging points reflect the significant expansion of waterlogging hazards in time and space. There were only seven recorded waterlogging events during the period from 1980 to 1989 , mainly at the junction of Yuexiu and Haizhu, while the events increased to a total of 51 in the next decade, from 1990 to 1999. Most of these events were concentrated in Yuexiu, with a small distribution in Liwan, Haizhu, and Tianhe. After 2000, the occurrence of waterlogging events increased to 113 main points by 2012. The distribution of these points expanded to the north and east, including Yuexiu, Tianhe, Haizhu, Baiyun, and other developed areas. There is a significant diffusion trend in time and space, and this trend continues to unfold over the next few years [15].

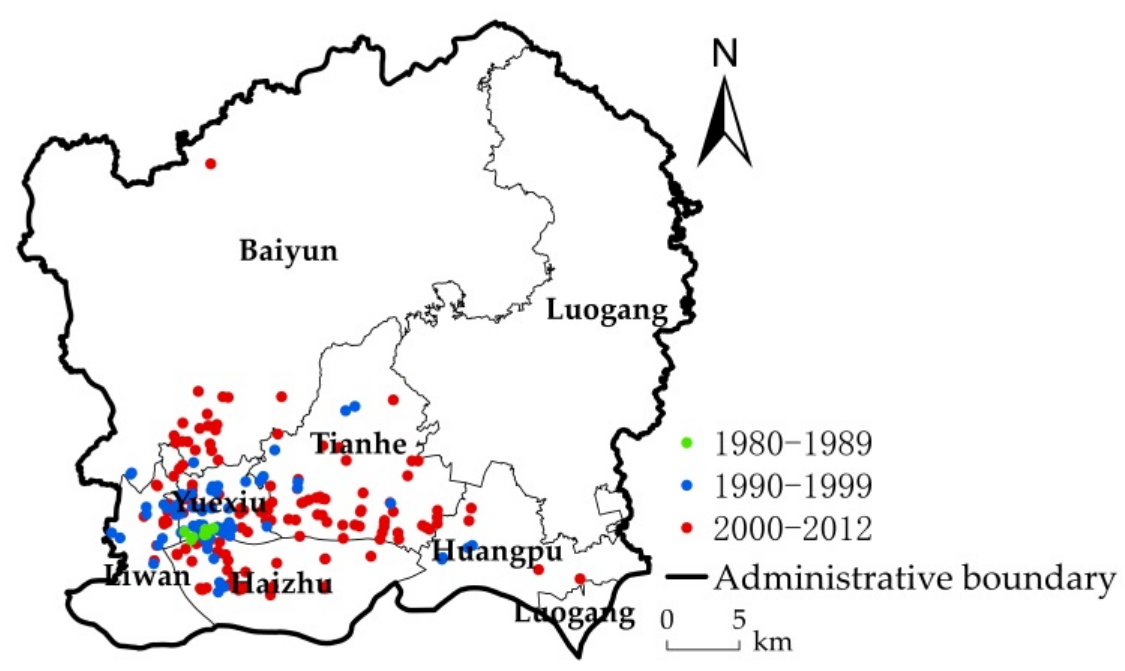

Figure 4. Spatiotemporal distribution of urban rainstorm waterlogging.

Average density distribution of urban rainstorm waterlogging in the three time periods was calculated using the KDE method (Figure $5 \mathrm{a}-\mathrm{c}$ ). The results show that the density increased continuously from the 1980s to 2000s. During the period of 1980-1989, the density of waterlogging events was relatively low and was located only in Yuexiu, Haizhu, and Liwan. From 1990 to 1999, the density of waterlogging events spread to the whole of Yuexiu, western Tianhe, western Haizhu, Liwan, and parts of Baiyun, and the density was much higher than that in the previous period. Compared with the period from 1990 to 1999, the density of waterlogging events showed a more 
obvious trend during the period of 2000-2012. The high density of rainstorm waterlogging events spread to the whole of Tianhe and Haizhu and the south of Baiyun, and the density value decreased slowly in the centre of Yuexiu. Therefore, urban rainstorm waterlogging in Guangzhou presented the tendency of adjacent diffusion in a single core, which is different from cities such as China's Shanghai and Shenzhen, Bangladesh's Khulna, India's Muzaffarpur, and so on. These cities also suffered from severe urban waterlogging disasters, but the occurrence of floods in these cities was more widely distributed in space without significant agglomeration [82-85].

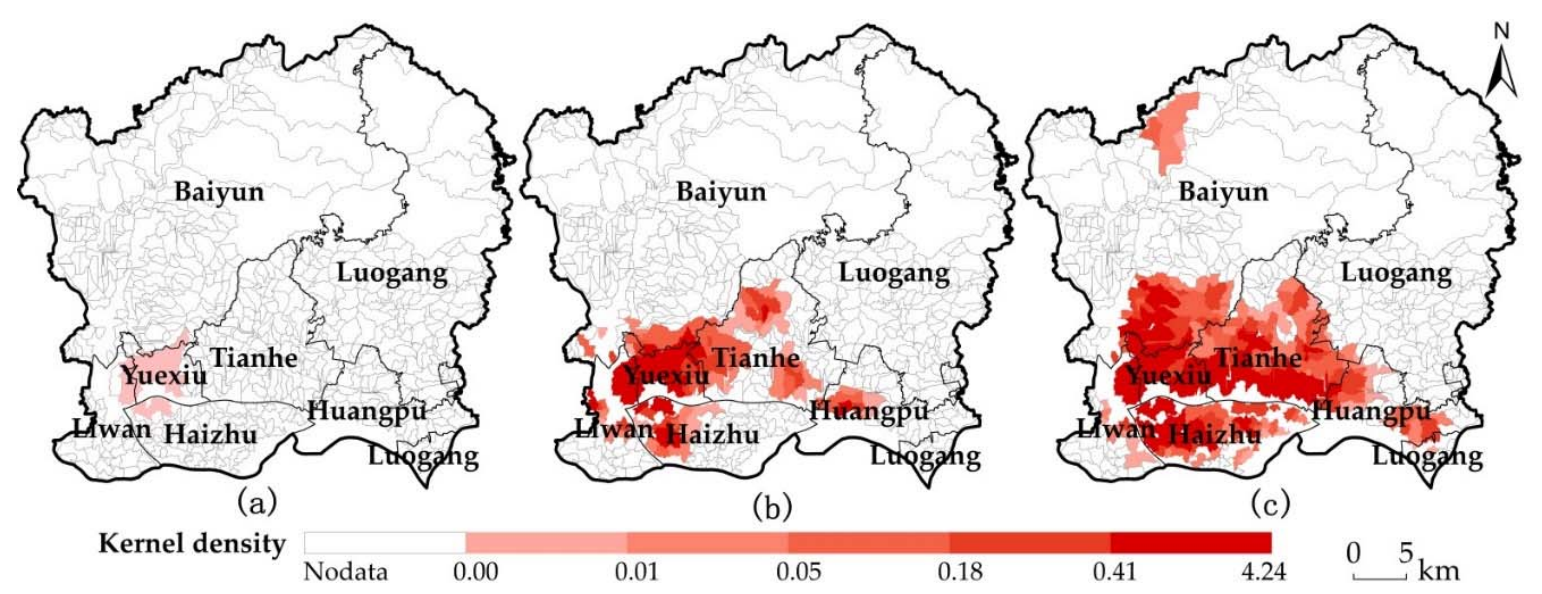

Figure 5. The average waterlogging density in Guangzhou city centre from 1990 to 2012 (a) 1980-1989;

(b) 1990-1999; (c) 2000-2012.

To explore the spatial correlation of different waterlogging events, Moran's I index was calculated respectively, based on the density distribution of waterlogging events (Table 2, Figure 6). The results show that the occurrence of storm waterlogging is not completely random but shows obvious spatial agglomeration, similar to that in the Chittagong city corporation area [86], Bangladesh. The spatial clustering of waterlogging gradually became stronger during the period 1980-2012. The Moran's I index during 2000-2012 is much higher than that in the other two periods.

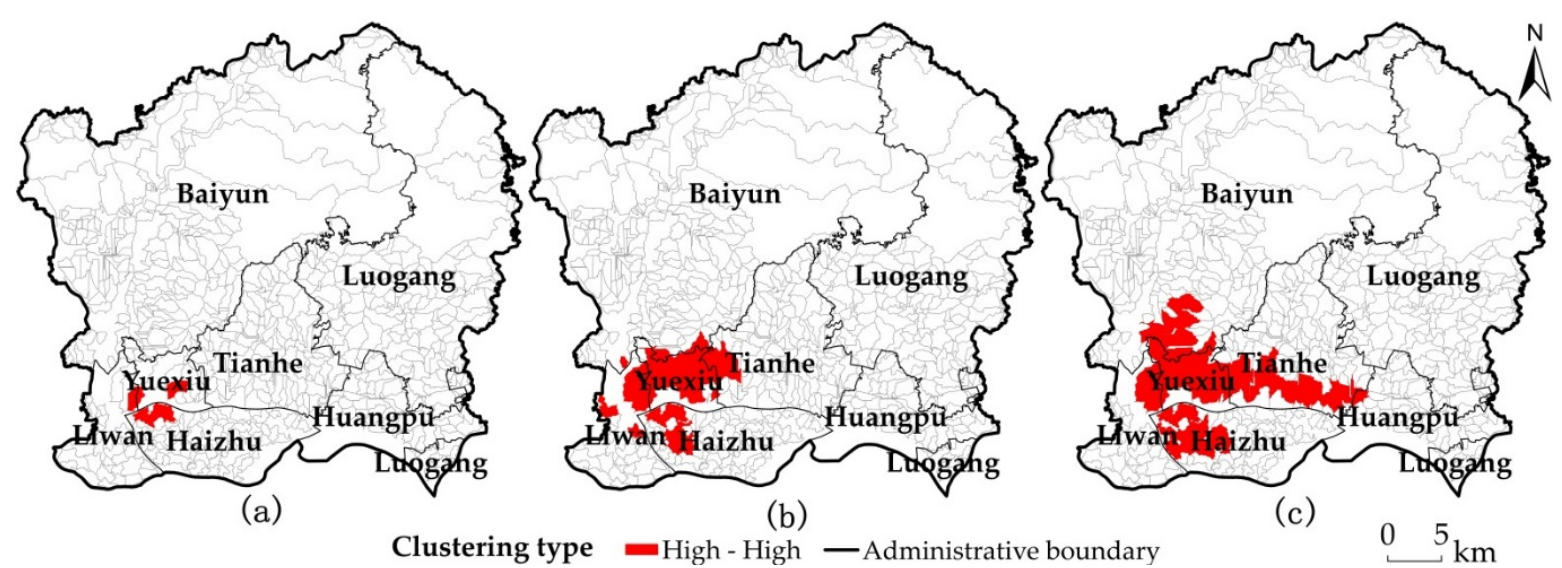

Figure 6. Agglomeration map of the average waterlogging density of Guangzhou city centre from 1990 to 2012.

In addition, the z-test values are well beyond the range of $-1.65 \sim 1.65$. In the agglomeration maps (Figure 6), the number of runoff plots with the "high-high" type of aggregation during the period 2000-2012 is significantly more than in the other two periods. Moreover, in the LISA cluster, the connectivity of the "high-high" type of runoff plot gradually increased. Runoff areas with a high degree of waterlogging can more easily increase the probability of waterlogging disaster in the 
nearby runoff plots. Therefore, it can be concluded that urban rainstorm waterlogging in downtown Guangzhou is spreading to adjacent areas in a spatial form of clustering.

Table 2. Moran's I index of average waterlogging density and impervious surface density from 1990 to 2012.

\begin{tabular}{ccccc}
\hline Research Period (Year) & Index & Moran's I & Z & P \\
\hline 1980-1989 & Average & 0.15 & 17.86 & 0.00 \\
1990-1999 & Waterlogging & 0.36 & 35.25 & 0.00 \\
2000-2012 & Density & 0.60 & 55.16 & 0.00 \\
\hline $1980-1989$ & Impervious & 0.73 & 66.32 & 0.00 \\
1990-1999 & Surface Density & 0.72 & 65.24 & 0.00 \\
2000-2012 & & 0.63 & 57.75 & 0.00 \\
\hline
\end{tabular}

In these three periods, the Moran's I index of the impervious surface density (Table 2) was 0.73 , 0.72 and 0.63 , and the z-test values were $66.32,65.27$ and 57.75 , respectively, all of which showed strong spatial autocorrelation at the $0.01 \%$ confidence level. The results indicate that the density of impervious surface in these three periods has different degrees of spatial agglomeration. Therefore, the traditional regression model based on a homogeneous hypothesis is difficult to apply, providing the basis for exploring the spatiotemporal variance of waterlogging caused by impervious surface expansion.

\subsection{Expansion of Impervious Surface}

In this study, the maximum likelihood method in the ENVI software is used to classify land use types. The overall accuracy of the classification is greater than $85 \%$, and the kappa coefficient is greater than 0.82 . Because this study, in reference to existing research, defines impervious surfaces using urban construction land [10], this study regards construction land as an impervious surface for analysis.

In the last 20 years, the urbanization mode of Guangzhou, a city with one of the most rapid rates of urbanization in the world, has been similar to that of cities such as Beijing, Shenzhen, and Hangzhou [87]. The land use transfer matrix (Table 3) shows that all kinds of land uses, except for green land, were converted mainly into urban impervious surfaces in the two phases of 1990-1999 and 1999-2010; agricultural and bare land were particularly heavily converted. In addition, the conversion of all kinds of land uses into impervious surfaces is higher during the latter phase than in the previous phase. In 1990, the city's impervious surface accounted for $27.76 \%$. In 1999, the city's impervious surface accounted for $30.68 \%$. In 2010 , the city's impervious surface reached $42.87 \%$ of the total. The impervious surface area increased continuously.

Table 3. Land transfer matrix in Guangzhou city centre from 1990 to $2012\left(\mathrm{~km}^{2}\right)$.

\begin{tabular}{ccccccc}
\hline \multirow{2}{*}{ Land Use } & \multicolumn{5}{c}{$\mathbf{1 9 9 9}$} \\
\cline { 3 - 6 } & & Green Land & Farmland & Water & Bare Land & ISA \\
\hline \multirow{3}{*}{1990} & Green land & 414.3 & 63.37 & 2.536 & 35.51 & 27.68 \\
& Farmland & 54.9 & 62.53 & 1.106 & 30.19 & 45.03 \\
& Water & 4.3794 & 1.5345 & 30.8385 & 1.9836 & 11.1069 \\
& Bare land & 59.4018 & 43.4781 & 2.8314 & 88.6734 & 67.2084 \\
& ISA & 26.1522 & 42.0021 & 8.0541 & 34.4637 & 292.7142 \\
\hline \multirow{2}{*}{2010} & Green land & 336.6144 & 35.3133 & 2.2788 & 23.9994 & 17.3367 \\
& Farmland & 106.1271 & 71.2143 & 2.7099 & 70.3044 & 46.4535 \\
& Water & 2.9826 & 1.6452 & 28.7883 & 2.5965 & 9.6786 \\
& Bare land & 32.9535 & 17.514 & 0.54 & 11.1564 & 13.8942 \\
& ISA & 80.5698 & 89.7192 & 11.1906 & 82.6209 & 360.3267 \\
\hline
\end{tabular}

Due to the special historical status of Guangzhou, its impervious surfaces expansion is affected by population and socio-economic factors, which is similar to Shenyang, Haikou, and Sanya. However, the policy factor is also an important factor [88-90]. 
Using the two-period standard deviation ellipse to explore the spatial orientation of added impervious surface, the long axes extend in the "northwest-southeast" direction, indicating that the added impervious surfaces of the two phases are mainly distributed in the northwest and southeast areas of the city centre (Figure 7). The barycentre of impervious surface is calculated to obtain the direction of migration. In the period of 1990-1999, the added impervious surfaces of Haizhu and Tianhe were denser, and the barycentre moves southeast with a migration distance of only $0.96 \mathrm{~km}$, driven by urban planning policies. The policy of deepening the readjustment of urban planning in 1984 and 1989 determined the development of the cluster structure and established the three cluster structures of the central, north, and east areas. Among them, there are two small groups in the central area (Yuexiu, Liwan, Haizhu, and Dongshan) and Tianhe (Wushan, Shipai, Yuancun, and Tianhe areas) [91]. Under the guidance of this policy, the central urban area in the 1990s was rapidly expanded. During this period, the impervious surface expansion mode is similar to that of Hangzhou, which was mainly filled internally, while there are differences between cities that expanded along the main road, such as Shenzhen and Dongguan [90]. Therefore, there was no obvious direction of impervious surface expansion in downtown Guangzhou during the period of 1990-1999.

After 2000, the added impervious surfaces in northern Baiyun, eastern Tianhe, and southern Luogang were the densest. The direction of the barycentre moved to the northeast, with a distance of $2.1 \mathrm{~km}$. These changes are also the result of Guangzhou's policy of urban development patterns established in 2001, "South Extension, North Excellence, East Progress and Western Union." Among these changes, the eastward development takes the construction of Zhujiang New Town (Central Business District) and Tianhe Asian Games Service Center as a driving force for urban development. The western union is a key development area in Liwan and Baiyun [92]. Under the guidance of this policy, the areas of impervious surfaces, such as large-scale commercial sites and urban road construction in northern Baiyun, eastern Tianhe, and southern Luogang, have greatly increased. Meanwhile, the impervious surface of Guangzhou is dominated mainly by marginal expansion and peripheral growth and shows obvious directionality in the north and east, which is different from the annular expansion of Beijing [93].

Based on the spatial distribution of the added impervious surface and the direction of the barycentre, it can be concluded that the impervious surface in both phases expanded around the city centre to the north and east, similar to a ring shape, with dense layers.

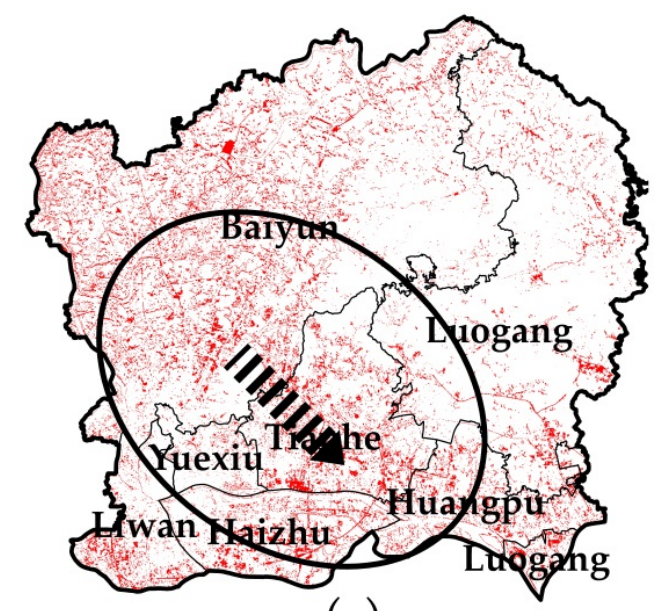

(a)

II Direction of barycenter migration $\square$ Tandard deviation ellipse

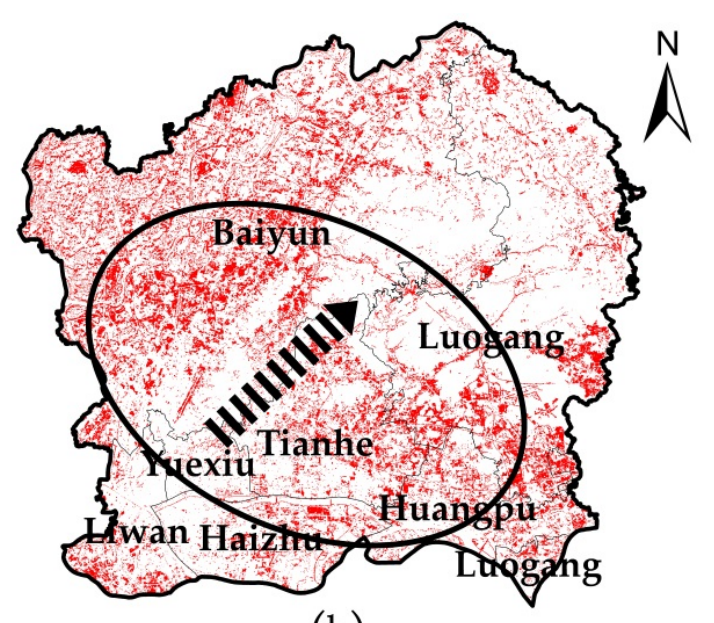

(b)

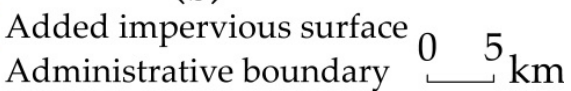

Figure 7. Added impervious surface of Guangzhou city centre (a) 1990-1999; (b) 1999-2012. 


\subsection{GWR Analysis of the Relationship between Urban Rainstorm Waterlogging and the Expansion of Impervious Surface}

The effect of GWR applied to the study of urban rainstorm waterlogging is appropriate. Because the locations of urban rainstorm waterlogging are generally not spatially random, the traditional regression analysis based on the assumption of homogeneous, independent and stochastic distribution is unsuitable for the simulation analysis of urban waterlogging. This characteristic also lays a foundation for GWR to integrate spatial location information and provides a guarantee for the validity of the model results. GWR obeys Tobler's first law of geography, fully considers the spatial location of adjacent factors, and solves the problem of spatial variance. Therefore, a single variable, impervious surface, is used to model it. Under the premise of random distribution of model residuals without spatial autocorrelation, the optimal model was obtained by following the AICC minimum principle (Table 4). The results show that events in the period of 1980-1989 are poorly modelled due to the lack of waterlogging data, and the model residuals obey normal distribution and spatial random distribution without spatial autocorrelation, with good simulation results in the latter two periods. The adjusted $R^{2}$ of two regression models was greater than 0.73 , indicating that the model fitting effect was better and more reliable. During the period from 1990-1999, the expansion of impervious surface can explain the spatial variance in urban rainstorm waterlogging with a confidence level of $73.3 \%$ in the regression model. Furthermore, this value reaches $77.4 \%$ during the period of 2000-2012. Therefore, the study analysed the models of the two periods of 1990-1999 and 2000-2012. Generally, the GWR model offers a good interpretation of the effects of impervious surface on urban rainstorm waterlogging.

Table 4. Related parameters of the geographical weighted regression.

\begin{tabular}{|c|c|c|c|c|c|}
\hline \multirow{2}{*}{$\begin{array}{c}\text { Research Period } \\
1990-1999\end{array}$} & \multicolumn{3}{|c|}{ Spatial Autocorrelation of Standard Residual } & \multirow{2}{*}{$\begin{array}{c}\mathbf{R}^{2} \\
0.871\end{array}$} & \multirow{2}{*}{$\frac{\text { Adjusted } \mathbf{R}^{\mathbf{2}}}{0.733}$} \\
\hline & Moran's I $=-0.008$ & $Z=-0.605$ & $\mathrm{P}=0.545$ & & \\
\hline 2000-2012 & Moran's I $=-0.179$ & $Z=-1.498$ & $\mathrm{P}=0.134$ & 0.864 & 0.774 \\
\hline
\end{tabular}

Due to the trend of urban rainstorm waterlogging spreading to the adjacent area in the form of spatial agglomeration, the density of urban rainstorm waterlogging in some districts is 0 , whose regression coefficient of the model is also 0 . Therefore, the study only analyses the runoff plots whose regression coefficient does not equal 0 , while the runoff plots with a regression coefficient of 0 are marked as 'no data.'

Comparing the spatial regression coefficients of impervious surface density over two periods (Figure 8a,b) allows the analysis of the spatiotemporal variance in the effects of impervious surface on urban rainstorm waterlogging. There were 79 runoff plots with regression coefficients greater than 0.09 from 1990 to 1999, located only in the west of both Yuexiu and Huangpu as well as in midwestern Haizhu. The impervious surface density in these areas is relatively high, showing a strong positive correlation between the density of waterlogging and the density of impervious surface. However, the characteristics of agglomeration are not obvious, and the spatial connectivity is weak, that is, there is an anisotropic change between impervious surface and urban rainstorm waterlogging during the period of 1990-1999. The number of the runoff plots whose regression coefficients are close to zero or even negative is over 150, such as those in the middle of Tianhe, Liwan, and Yuexiu, as well as western Haizhu. That number does not accord with the proposal that the greater the density of impervious surface is, the greater the density of waterlogging. The result indicates that the impervious surface expansion in these areas is not enough to cause urban waterlogging, but other factors have a dominant influence. Although a number of runoff plot regression coefficients were close to zero or even negative between 2000 and 2012, the spatial regression coefficients of impervious surface in the remaining areas of Yuexiu, Haizhu, and Tianhe rose from negative to positive during this period. The spatial regression coefficient of impervious surface in these districts outside of the city centre's density area also rose from zero to positive. The impervious surfaces in these runoff plots become 
a disaster-causing factor. This result shows that the influence of impervious surface expansion on urban waterlogging is increasing. In addition, the plots with a regressive coefficient greater than 1.335 increased to 208 during this period, which presented obvious spatial agglomeration, and these runoff plots were connected. The most obvious ones are located in the southeast of Yuexiu, the south of Tianhe and the central-western area of Haizhu. Generally, the spatial regression coefficient decreases from the city centre to the surrounding urban areas, which is similar to the decreasing direction of the impervious surface.

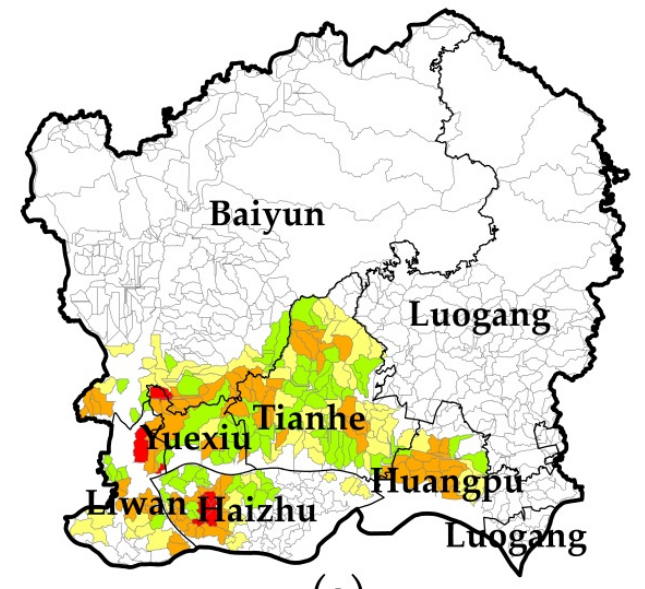

(a)

Regression coefficients

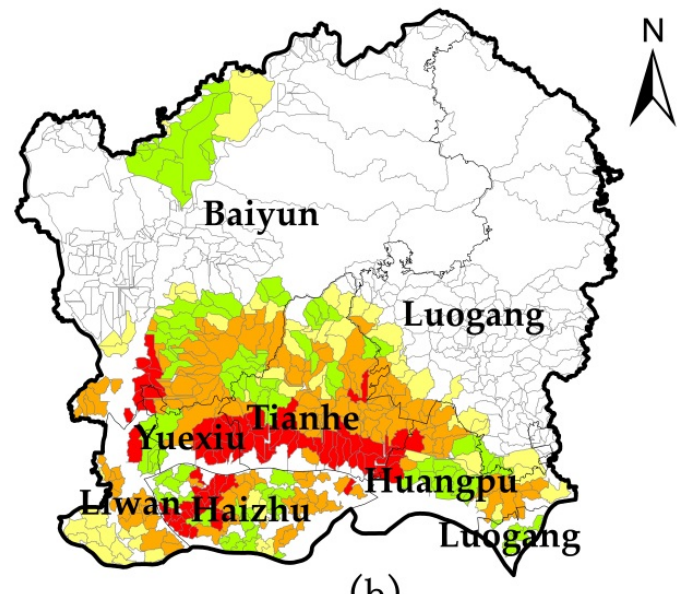

(b)

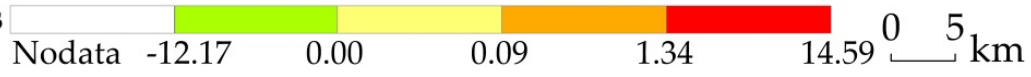

Figure 8. Spatial distribution of the regression coefficients of impervious surface density in the GWR model (a) 1990-1999; (b) 1999-2012.

As shown by the analysis above, impervious surfaces have a huge impact on urban rainstorm waterlogging, although that impact is different in different areas. This spatiotemporal variance is largely the result of large urban projects. From 1990 to 1999, the positive correlation between impervious surface and urban waterlogging only appeared in certain older urban areas, including the west of both Yuexiu and Haizhu, which experienced a series of major urban construction projects before 2000, such as the facilities for the Guangzhou Sixth National Games and the Ninth National Games. After 2000, local government put forward the concept of "two hearts and four cities" for the Guangzhou Asian Games in 2010. The policy promoted Tianhe as the centre in order to improve the Asian games service facilities, also resulting in increased urban construction in Baiyun, Liwan, Huangpu, and so on [94]. This policy continually increased the density of impervious surfaces in these areas, and the connection of impervious surfaces became much stronger. As a result, urban surface hardening has become increasingly serious, which significantly increases the risk of waterlogging in the southeast of Yuexiu, the south of Tianhe, and the central-western area of Haizhu. Therefore, the renovation of large-scale urban projects is an important cause of the spatiotemporal variance in the effects of impervious surfaces on urban rainstorm waterlogging.

The spatial regression intercept in the GWR model indicates the contribution of other factors to the average density of waterlogging when the density of the impervious surface is zero. The impervious surface density in this area is not sufficient to cause the current urban waterlogging status when the intercept is positive. Other factors increase the possibility of waterlogging. When the intercept is negative, it indicates that there are other factors that reduce the contribution of the impervious surfaces to urban rainstorm waterlogging. Comparing the spatial distribution of regression intercepts of GWR models in two periods (Figure 9) reveals spatial variance in the impact of other factors on urban rainstorm waterlogging during the period of 1990-2012. The areas with negative intercepts in both periods were dominated by Liwan and central-western Haizhu, indicating that other factors inhibit impervious surfaces from promoting urban rainstorm waterlogging in these areas. In contrast, in many 
areas, the spatial intercepts continued to be positive, including the southern part of Baiyun, the western part of Yuexiu, the western part of Haizhu, and the middle of Tianhe, showing that other factors and impervious surfaces always intensified urban storm waterlogging. The spatial regression intercepts of the central part of Huangpu and the northeast and west of Tianhe during the two periods changed from negative values to positive values. This result shows that, in addition to the increase in density of impervious surfaces, other factors also contribute to the urban waterlogging storm, and the intensity of this effect is increasing. Opposite to these results, the spatial regression intercepts in eastern Yuexiu and southern Tianhe changed from positive to negative. The development and construction of these areas led to the sharp increase of impervious surface density, changing the original terrain structure. As a result, the impact of these factors on waterlogging has gradually weakened. Furthermore, some new districts affected by waterlogging, such as northern Baiyun and central Haizhu, have positive spatial regression intercepts, indicating that other factors exacerbate urban waterlogging in these areas.

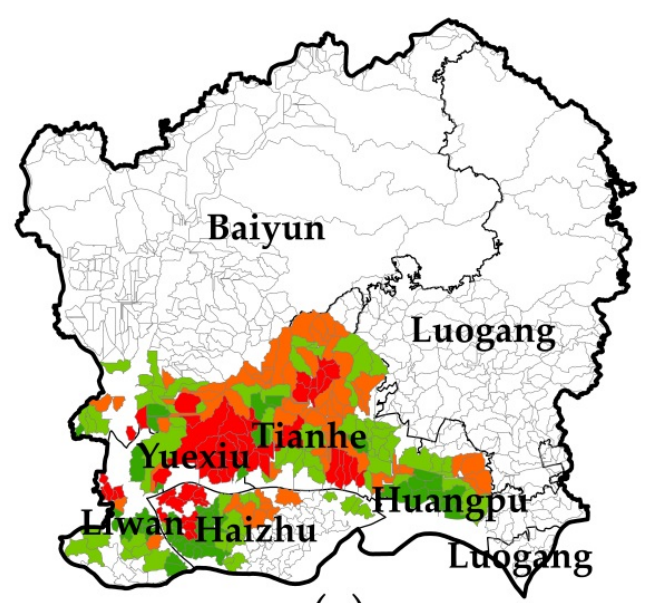

(a)

\section{Regression intercept}

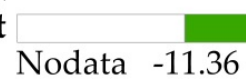

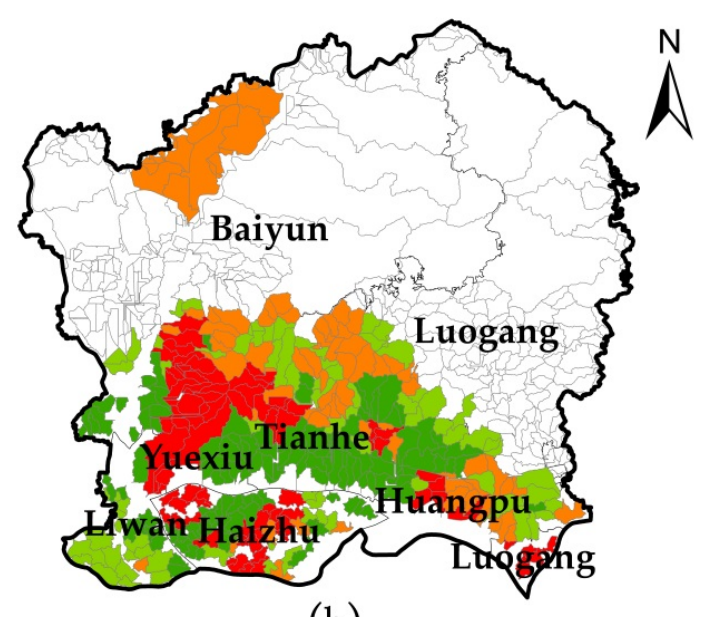

(b)

Figure 9. Spatial distribution of the regression intersect of GWR model (a) 1990-1999; (b) 1999-2012.

As shown by the analysis above, in addition to the spatial variance of waterlogging caused by impervious surfaces, other factors also affect this characteristic of waterlogging, such as green area ratio, road network density, poor area, and so on [83]. It can also be seen from the above that urban rainstorm waterlogging mainly occurs in the city centre, where the increment of impervious surface density is relatively low. Due to the complexity of the causes of waterlogging, the reason for such discrepancy can be explained in three aspects. First, the standard of drainage pipe network equipment in the downtown area is low. In the drainage network with a total length of approximately $6000 \mathrm{~km}$, $83 \%$ were once a year of heavy rain, and only $9 \%$ in two years of heavy rain. In particular, the drainage network in the old main urban areas was installed a long time ago, the standards used in establishing the network are inconsistent, and the drainage capacity is insufficient during rainfall. Second, the main urban area is near the main course of the Pearl River. In five-year and ten-year heavy rain event areas, or even more serious rainfall, urban rainstorm waterlogging will be greatly accelerated, resulting in intrusion of water as the water level of the river channel rises rapidly. Finally, the topography has an impact on the surface runoff direction, and the surface runoff is generally collected in low-lying and low-grade areas. Waterlogging is generally prone to occurring when rainfall exceeds the drainage conditions in these areas. As shown in the slope map (Figure 10), the slope of the old main urban areas is low, with an average slope of 4.46, and the average slope of the whole downtown area is 5.28, which contributes to this area becoming a series of rainfall runoff zones. Because impervious surfaces expand to the north and east around the drainage network installation in a manner of the circle and dense plane, the area's permeability is relatively weak. The time it takes for surface runoff to form is 
greatly reduced. In addition, for the low topographical areas, the surface runoff rapidly forms and drastically flows into the city centre, increasing pressure on the drainage network and accelerating the river waterline so that it cannot properly address the effects of rainstorms, leading to advance flooding peaks as well as increased probability of waterlogging.

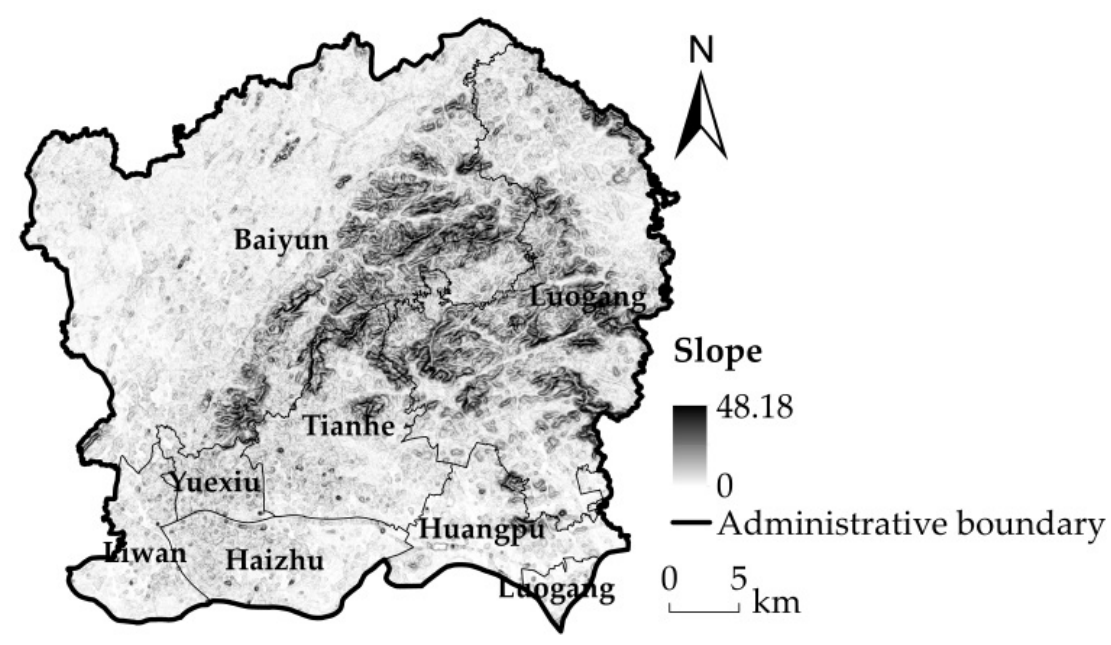

Figure 10. The slope of Guangzhou.

The added impervious surface density and the regression coefficients of the GWR are divided into four levels using the natural breaks classification method. The two groups with larger values are classified as the higher level $(\mathrm{H})$, while the other groups are classified as the lower level $(\mathrm{L})$. The first " $\mathrm{L}$ " and " $\mathrm{H}$ " represent the lower and higher values of the added impervious surface density, respectively. The second " $\mathrm{L}$ " and " $\mathrm{H}$ " represent the lower and higher values of the regression coefficients of the GWR, respectively. Figure 11 shows that the area with a high GWR regression coefficient, including " $\mathrm{LH}^{\prime}$ and "HH," has obvious characteristics of agglomeration of impervious surface density. The districts with lower impervious surface density and higher GWR regression coefficients (LH) are located in northern Baiyun, western Haizhu, eastern Liwan, and eastern Yuexiu and other areas near the city centre. In contrast, the eastern part of Tianhe and the Huangpu border areas show a double-high phenomenon $(\mathrm{HH})$, that is, the increment of impervious surface density is high, and the GWR model also has a larger regression coefficient. The other two types were distributed discretely without obvious features.

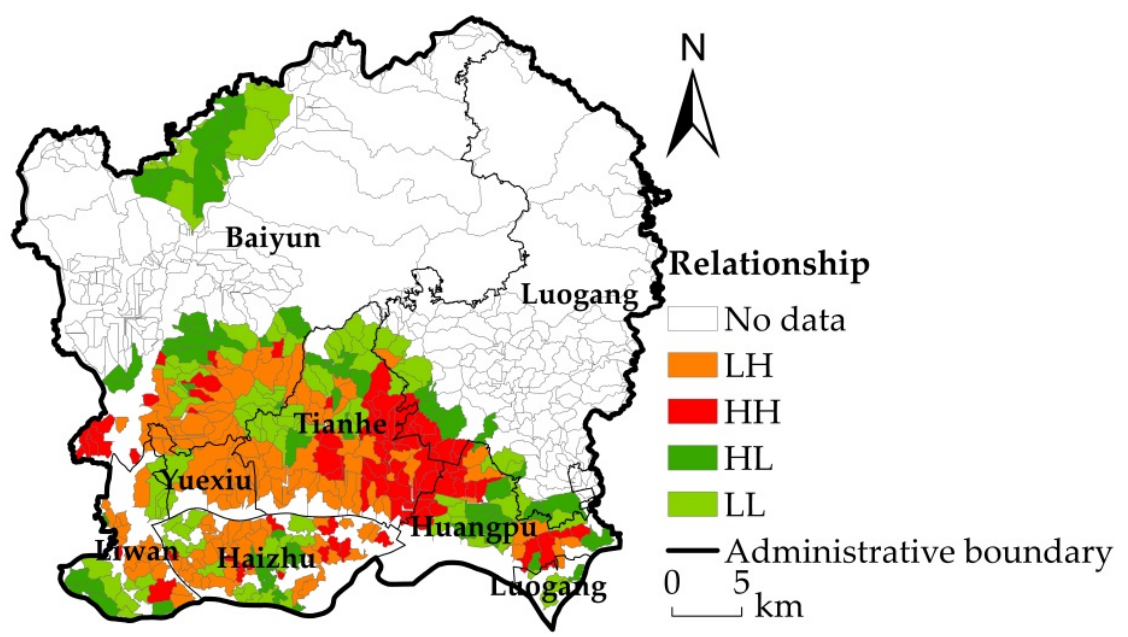

Figure 11. The relationship between the regression coefficients of the GWR model and added impervious surface. 


\section{Conclusions and Discussion}

Since the well-known "open-door" policy and economic reform were adopted in 1978, China has experienced a rapid urbanization process in many cities. This rapid urbanization process leads to an increase in the area and density of impervious surfaces in urban regions and, accordingly, to the emergence of urban rainstorm waterlogging risks in these cities. Optimizing the spatial pattern of impervious surfaces through urban renewal is an effective channel through which to attenuate urban waterlogging risk for developed urban areas. The most important step for optimizing the spatial pattern of impervious surfaces is to understand the mechanism of the impact of urbanization processes on urban waterlogging and to determine suitable regions for urban renewal. This study focuses on this issue to analyse the spatiotemporal pattern change in urban impervious surfaces and the characteristics of the spatiotemporal agglomeration of waterlogging in a case study of Guangzhou. The study area was divided into urban runoff plots with areas ranging from $0.8-1.5 \mathrm{~km}^{2}$ to meet the area requirement of the control unit of urban renewal planning. Additionally, this research introduced GWR to explore the spatiotemporal variance of the impact of impervious surface expansion on urban rainstorm waterlogging during the period of 1990-2012.

During the period from 1980 to 2012, urban rainstorm waterlogging events significantly expanded to the north and east in a dense and circular pattern surrounding the city centre, similar to the impervious surface expansion affected by the development policies. With the increasing proportion of impervious surfaces in urban development, the underlying surfaces in cities have undergone tremendous changes, the original natural landscapes have been continuously transformed, and urban surface hardening has become increasingly serious. This change not only rapidly reduces the ability to store and infiltrate rain in the urban environment but also shortens the time for rain catchment, thereby aggravating the traffic load of urban drainage systems and greatly increasing the risk of urban waterlogging and the difficulty of urban renewal planning as well.

Understanding the mechanism of the impact of urban development on urban disasters is key to improving urban disaster resilience [95]. This research dealt with the crucial issue of spatiotemporal variance assessment of urban rainstorm waterlogging affected by impervious surface expansion, providing the reference for urban renewal strategy-making for urban rainstorm waterlogging prevention and control. Compared with Hui Zhang's (2018) results [56], the research unit of this paper fully considered the terrain conditions and combined urban planning units to divide the runoff community, which is an important unit to study urban waterlogging, so that the results provided a better basis for urban renewal planning. Moreover, time series analysis better reflects the spatiotemporal variance of the impact of impervious surfaces on waterlogging. On this basis, the spatiotemporal variance of the effect of impervious surfaces on urban rainstorm waterlogging can be effectively explored from the perspective of local space. The result of spatiotemporal variance analysis can provide useful information for urban renewal strategy-making for different runoff plots. Major urban engineering construction will intensify the induction effect of impervious surfaces on urban rainstorm waterlogging, which is most intense in the runoff plots in the southeast of Yuexiu, the south of Tianhe and the central-western area of Haizhu. These urban runoff plots will be the primary objects of urban renewal for urban rainstorm waterlogging prevention and control. Meanwhile, the government needs to strictly control the urban construction in central Tianhe, southern Baiyun and eastern Liwan, which currently have less propensity to waterlogging, to reduce the impact of impervious surfaces on urban rainstorm waterlogging.

This research realizes the application exploration of GWR in rainstorm waterlogging analysis. GWR is appropriate for use in assessing the spatiotemporal variance of urban rainstorm waterlogging affected by impervious surface expansion. However, the expansion of impervious surfaces is just one of the causes of urban rainstorm waterlogging. Therefore, future research can consider the factors such as urban pipe networks and land type to explore the spatial variance between different disaster factors for waterlogging. This study provides an example for the application of GWR in the study of urban rainstorm waterlogging. It is hoped that this model can be popularized in this field. 
In general, unlike studies conducted from the viewpoint of large scale and global space, the spatiotemporal variance of the impacts of impervious surfaces on urban rainstorm waterlogging from the local spatial perspective can provide a more accurate decision-making basis for urban renewal planning. Moreover, this research showed the spatiotemporal variance of the effects of the impervious surfaces on urban rainstorm waterlogging and provided the possibility of realizing urban rainstorm waterlogging prevention from the perspective of the spatial layout optimization of impervious surfaces.

Author Contributions: H.Y. completed the experiments and the manuscript. Y.Z. proposed the basic idea, designed the approaches involved in this study and modified the manuscript. Y.F. and L.L. provided the useful suggestions on designing the approaches.

Funding: This research was funded by the National Natural Science Foundation of China (No. 41871292), the China Postdoctoral Science Foundation (No. 2018M630962), and the Science and Technology Program of Guangzhou, China (No. 201803030034, 201802030008).

Acknowledgments: The authors would like to express gratitude to Muhammad Rizwan for his valuable support throughout this study.

Conflicts of Interest: The authors declare no conflict of interest.

\section{References}

1. Chen, P.; Zhang, J.; Jiang, X.; Liu, X.; Bao, Y.; Sun, Y. Scenario simulation-based assessment of trip difficulty for urban residents under rainstorm waterlogging. Int. J. Environ. Res. Public Health 2012, 9, 2057-2074. [CrossRef] [PubMed]

2. Wang, X.; Xie, H. A review on applications of remote sensing and geographic information systems (GIS) in water resources and flood risk management. Water 2018, 10, 608. [CrossRef]

3. Tan, X.; Shu, Y.; Lian, Y.; Zhao, Y.; Fu, Y. A spatial assessment of urban waterlogging risk based on a weighted naïve Bayes classifier. Sci. Total Environ. 2018, 630, 264-274.

4. Hu, S.L.; Han, C.F.; Meng, L.P. A scenario planning approach for propositioning rescue centers for urban waterlog disasters. Comput. Ind. Eng. 2015, 87, 425-435. [CrossRef]

5. Yin, J.; Ye, M.; Yin, Z.; Xu, S. A review of advances in urban flood risk analysis over China. Stoch. Environ. Res. Risk Assess. 2015, 29, 1063-1070. [CrossRef]

6. Quan, R.; Zhang, L.; Min, L.; Min, L.; Wang, J.; Niu, H. Risk assessment of rainstorm waterlogging on subway in central urban area of Shanghai, China based on scenario simulation. Nat. Hazards 2014, 73, 1569-1585. [CrossRef]

7. Zhang, X.; Hu, M.; Chen, G.; Xu, Y. Urban rainwater utilization and its role in mitigating urban waterlogging problems-A case study in Nanjing, China. Water Resour. Manag. 2012, 26, 3757-3766. [CrossRef]

8. Bei-Bei, H.U.; Zhou, J.; Wang, J.; Shi-Yuan, X.U.; Meng, W.Q. Risk assessment on rainstorm waterlogging of Tianjin Binhai new area based on scenario simulation. Sci. Geogr. Sin. 2012, 32, 846-852.

9. Chen, Z.; Yin, L.; Chen, X.; Wei, S.; Zhu, Z. Research on the characteristics of urban rainstorm pattern in the humid area of Southern China: A case study of Guangzhou City. Int. J. Climatol. 2016, 35, 4370-4386. [CrossRef]

10. Li, B.; Zhao, Y.; Fu, Y. Spatio-temporal characteristics of urban stormwaterlogging in Guangzhou and the impact of urban growth. Geo-Inf. Sci. 2015, 17, 445-450.

11. Zhang, H.; Wu, C.; Chen, W. Assessing the impact of climate change on the waterlogging risk in coastal cities: A case study of Guangzhou, South China. J. Hydrometeorol. 2017, 18, 1549-1562. [CrossRef]

12. Wang, P.; Deng, X.; Zhou, H.; Qi, W. Responses of urban ecosystem health to precipitation extreme: A case study in Beijing and Tianjin. J. Clean. Prod. 2018, 177, 124-133. [CrossRef]

13. Gomathi, R.; Rao, P.N.G.; Chandran, K.; Selvi, A. Adaptive responses of sugarcane to waterlogging stress: An over view. Sugar Tech 2015, 17, 325-338. [CrossRef]

14. Wu, X.; Yu, D.; Chen, Z.; Wilby, R.L. An evaluation of the impacts of land surface modification, storm sewer development, and rainfall variation on waterlogging risk in Shanghai. Nat. Hazards 2012, 63, $305-323$. [CrossRef]

15. Schmitt, T.G.; Thomas, M.; Ettrich, N. Analysis and modeling of flooding in urban drainage systems. J. Hydrol. 2004, 299, 300-311. [CrossRef] 
16. Zhou, Y.; Li, T. Case study: The performance and design outline of a buffering stormwater drainage system for a low-lying area. Water Environ. J. 2010, 22, 199-205. [CrossRef]

17. Hu, M.; Zhang, X.; Siu, Y.L.; Li, Y.; Tanaka, K.; Yang, H.; Xu, Y. Flood mitigation by permeable pavements in Chinese sponge city construction. Water 2018, 10, 172. [CrossRef]

18. Bryndal, T.; Franczak, P.; Kroczak, R.; Cabaj, W.; Kołodziej, A. The impact of extreme rainfall and flash floods on the flood risk management process and geomorphological changes in small Carpathian catchments: A case study of the Kasiniczanka river (outer Carpathians, Poland). Nat. Hazards 2017, 88, 1-26. [CrossRef]

19. Deverel, S.J.; Ingrum, T.; Leighton, D. Present-day oxidative subsidence of organic soils and mitigation in the Sacramento-San Joaquin Delta, California, USA. Hydrogeol. J. 2016, 24, 1-18. [CrossRef] [PubMed]

20. Pietrucha-Urbanik, K. Failure analysis and assessment on the exemplary water supply network. Eng. Fail. Anal. 2015, 57, 137-142. [CrossRef]

21. Pietrucha-Urbanik, K. Assessing the Costs of Losses Incurred as a Result of Failure; Springer: Cham, Switzerland, 2016; pp. 355-362.

22. Tabesh, M.; Soltani, J.; Farmani, R.; Savic, D. Assessing pipe failure rate and mechanical reliability of water distribution networks using data-driven modeling. J. Hydroinform. 2009, 11, 1-17. [CrossRef]

23. Martin-Mikle, C.J.; de Beurs, K.M.; Julian, J.P.; Mayer, P.M. Identifying priority sites for low impact development (lid) in a mixed-use watershed. Landsc. Urban Plan. 2015, 140, 29-41. [CrossRef]

24. Maryland Department of Environmental Resources. Low-Impact Development Design Strategies: An Integrated Design Approach; Maryland Department of Environmental Resources: Prince Geogre's County, MD, USA, 1999.

25. Gu, L.; Gu, N. Urban waterlogging and stormwater management. Appl. Mech. Mater. 2014, 587-589, 554-557. [CrossRef]

26. Dietz, M.E. Low impact development practices: A review of current research and recommendations for future directions. Water Air Soil Pollut. 2007, 186, 351-363. [CrossRef]

27. Lanarc Consultants Ltd.; KWL Ltd.; Ngan, G. Stormwater Source Control Design Guidelines 2005; Lanarc Consultants Ltd.: Nanaimo, BC, Canada; KWL Ltd.: Hull, UK, 2005.

28. Joksimovic, D.; Alam, Z. Cost efficiency of low impact development (lid) stormwater management practices. Procedia Eng. 2014, 89, 734-741. [CrossRef]

29. Sin, J.; Jun, C.; Zhu, J.H.; Yoo, C. Evaluation of flood runoff reduction effect of lid (low impact development) based on the decrease in CN: Case studies from Gimcheon Pyeonghwa District, Korea. Procedia Eng. 2014, 70, 1531-1538. [CrossRef]

30. Ben, U. Storm Water; Prentice Hall: London, UK, 1994.

31. Yazdi, J.; Salehi Neyshabouri, S.A.A. Identifying low impact development strategies for flood mitigation using a fuzzy-probabilistic approach. Environ. Model. Softw. 2014, 60, 31-44. [CrossRef]

32. Sang, Y.-F.; Yang, M. Urban waterlogs control in China: More effective strategies and actions are needed. Nat. Hazards 2017, 2017, 1291-1294. [CrossRef]

33. Pindado, M.Á.; Aguado, A.; Josa, A. Fatigue behavior of polymer-modified porous concretes. Cem. Concr. Res. 1999, 29, 1077-1083. [CrossRef]

34. Yousef, Y.; Hvitved-Jacobsen, T.; Wanielista, M.; Harper, H. Removal of contaminants in highway runoff flowing through Swales. Sci. Total Environ. 1987, 59, 391-399. [CrossRef]

35. Doug, B.; Hitesh, D.; James, L.; Paul, M. Report on the Environmental Benefits and Costs of Green Roof Technology for the City of Toronto; Ryerson University: Toronto, ON, Canada, 2005.

36. Lai, L.W.C.; Chau, K.W.; Cheung, P.A.C.W. Urban renewal and redevelopment: Social justice and property rights with reference to Hong Kong's constitutional capitalism. Cities 2018, 74, 240-248. [CrossRef]

37. Pérez, M.G.R.; Laprise, M.; Rey, E. Fostering sustainable urban renewal at the neighborhood scale with a spatial decision support system. Sustain. Cities Soc. 2018, 38, 440-451. [CrossRef]

38. Zhao, P. Sustainable urban expansion and transportation in a growing megacity: Consequences of urban sprawl for mobility on the urban fringe of Beijing. Habitat Int. 2010, 34, 236-243. [CrossRef]

39. Zheng, H.W.; Shen, G.Q.; Wang, H.; Hong, J. Simulating land use change in urban renewal areas: A case study in Hong Kong. Habitat Int. 2015, 46, 23-34. [CrossRef]

40. Zheng, H.W.; Shen, G.Q.; Wang, H. A review of recent studies on sustainable urban renewal. Habitat Int. 2014, 41, 272-279. [CrossRef] 
41. Barosio, M.; Eynard, E.; Marietta, C.; Marra, G.; Melis, G.; Tabasso, M. From urban renewal to urban regeneration: Classification criteria for urban interventions. Turin 1995-2015: Evolution of planning tools and approaches. J. Urban Regen. Renew. 2016, 9, 367-380.

42. Ramamurthy, P.; Bou-Zeid, E. Contribution of impervious surfaces to urban evaporation. Water Resour. Res. 2014, 50, 2889-2902. [CrossRef]

43. Ridd, M.K. Exploring a V-I-S (vegetation-impervious surface-soil) model for urban ecosystem analysis through remote sensing: Comparative anatomy for cities. Int. J. Remote Sens. 1995, 16, 2165-2185. [CrossRef]

44. Xu, R.; Zhang, H.; Lin, H. Annual dynamics of impervious surfaces at city level of pearl river delta metropolitan. Int. J. Remote Sens. 2018, 39, 3537-3555. [CrossRef]

45. Zhang, L.; Zhang, M.; Yao, Y. Mapping seasonal impervious surface dynamics in Wuhan urban agglomeration, China from 2000 to 2016. Int. J. Appl. Earth Obs. Geoinf. 2018, 70, 51-61. [CrossRef]

46. Verstraeten, G.; Poesen, J. The nature of small-scale flooding, muddy floods and retention pond sedimentation in central Belgium. Geomorphology 1999, 29, 275-292. [CrossRef]

47. Bhaskar, A.S.; Jantz, C.; Welty, C.; Drzyzga, S.A.; Miller, A.J. Coupling of the water cycle with patterns of urban growth in the Baltimore Metropolitan Region, United States. J. Am. Water Resour. Assoc. 2016, 52, 1-15. [CrossRef]

48. Urbonas, B.R.; Doerter, J.T. Master planning for stream protection in urban watersheds. Water Sci. Technol. J. Int. Assoc. Water Pollut. Res. 2005, 51, 239-247. [CrossRef]

49. Brun, S.E.; Band, L.E. Simulating runoff behavior in an urbanizing watershed. Comput. Environ. Urban Syst. 2000, 24, 5-22. [CrossRef]

50. Booth, D.B.; Jackson, C.R. Urbanization of aquatic systems: Degradation thresholds, stormwater detection, and the limits of mitigation. J. Am. Water Resour. Assoc. 2010, 33, 1077-1090. [CrossRef]

51. Rose, S.; Peters, N.E. Effects of urbanization on streamflow in the Atlanta Area (Georgia, USA): A comparative hydrological approach. Hydrol. Process. 2001, 15, 1441-1457. [CrossRef]

52. Su, W.; Ye, G.; Yao, S.; Yang, G. Urban land pattern impacts on floods in a new district of China. Sustainability 2014, 6, 6488-6508. [CrossRef]

53. Zheng, P.Q.; Baetz, B.W. GIS-based analysis of development options from a hydrology perspective. J. Urban Plan. Dev. 1999, 125, 164-180. [CrossRef]

54. Poff, L.R.; Bledsoe, B.P.; Cuhaciyan, C.O. Hydrologic variation with land use across the contiguous united states: Geomorphic and ecological consequences for stream ecosystems. Geomorphology 2006, 79, 264-285. [CrossRef]

55. Mejía, A.I.; Moglen, G.E. Spatial patterns of urban development from optimization of flood peaks and imperviousness-based measures. J. Hydrol. Eng. 2009, 14, 416-424. [CrossRef]

56. Zhang, H.; Cheng, J.; Wu, Z.; Li, C.; Qin, J.; Liu, T. Effects of impervious surface on the spatial distribution of urban waterlogging risk spots at multiple scales in Guangzhou, South China. Sustainability 2018, 10, 1589. [CrossRef]

57. Tobler, W.R. A computer movie simulating urban growth in the Detroit region. Econ. Geogr. 1970, 46, $234-240$. [CrossRef]

58. Guan, Y.; Zheng, F.; Zhang, P.; Qin, C. Spatial and temporal changes of meteorological disasters in China during 1950-2013. Nat. Hazards 2015, 75, 2607-2623. [CrossRef]

59. Thorn, A.M.; Wake, C.P.; Grimm, C.D.; Mitchell, C.R.; Mineau, M.M.; Ollinger, S.V. Development of scenarios for land cover, population density, impervious cover, and conservation in New Hampshire, 2010-2100. Ecol. Soc. 2017, 22. [CrossRef]

60. Cheung, L.T.O.; Hui, D.L.H. Influence of residents' place attachment on heritage forest conservation awareness in a peri-urban area of Guangzhou, China. Urban For. Urban Green. 2018, 33, 37-45. [CrossRef]

61. HRNUO. 2017 Latest National Top 100 Cities GDP Rankings. Available online: https:/ / www.hrnuo.com/ about/xinwenzixun/314.html (accessed on 4 February 2017).

62. Liu, X. Waterlogging Points in Guangzhou 30 Years Spread 16 Times. Available online: http://gd.qq.com/a/ 20160105/008699.htm (accessed on 5 January 2016).

63. Huang, H.; Chen, X.; Zhu, Z.; Xie, Y.; Liu, L.; Wang, X.; Wang, X.; Liu, K. The changing pattern of urban flooding in Guangzhou, China. Sci. Total Environ. 2017, 622-623, 394. [CrossRef] [PubMed]

64. Zimmerman, C.L.; Runkle, J.R. Using ecological land units for conservation planning in a southwestern Ohio Watershed. Nat. Areas J. 2010, 30, 27-38. [CrossRef] 
65. Zhang, S.L.; Gan, J.Y.; Zeng, Q.L.; Lu, G.N. Automatic compartmentalization of urban rainwater catchments on water outlet supported by GIS technology. J. Hydraul. Eng. 2007, 38, 325-329.

66. Xue, F.; Sheng, J.; Qian, H. Research on classification of Rainstormwatershed delineation approach for plain urban regions. Geo-Inf. Sci. 2015, 17, 462-468.

67. Wang, Z.; Shi, Y.; Sun, X. Exploration of urban planning administrative map in Guangzhou. City Plan. Rev. 2003, 27, 41-47.

68. Botev, Z.I.; Grotowski, J.F.; Kroese, D.P. Kernel density estimation via diffusion. Ann. Stat. 2010, 38, 2916-2957. [CrossRef]

69. Wang, Y.; He, H. Spatial Data Analysis Method; Science Press: Beijing, China, 2007.

70. Moran, P.A. Notes on continuous stochastic phenomena. Biometrika 1950, 37, 17-23. [CrossRef] [PubMed]

71. Ord, J.K.; Getis, A. Local spatial autocorrelation statistics: Distributional issues and an application. Geogr. Anal. 1995, 27, 286-306. [CrossRef]

72. Anselin, L. Local indicators of spatial association-Lisa. Geogr. Anal. 1995, 27, 93-115. [CrossRef]

73. Mitchel, A.E. The ESRI Guide to GIS Analysis, Volume 2: Spartial Measurements and Statistics; ESRI Guide to GIS Analysis; ESRI Press: Redlands, CA, USA, 2005.

74. Fotheringham, A.S.; Brunsdon, C.; Charlton, M. Geographically Weighted Regression: The Analysis of Spatially Varying Relationships; International Union of Crystallography: Chester, UK, 2002; pp. 125-126.

75. Hu, M.; Li, Z.; Wang, J.; Lin, J.; Liao, Y.; Lai, S.; Guo, Y.; Dan, Z.; Yang, W. Determinants of the incidence of hand, foot and mouth disease in China using geographically weighted regression models. PLOS ONE 2012, 7, e38978. [CrossRef] [PubMed]

76. Luo, J.; Du, P.; Samat, A.; Xia, J.; Che, M.; Xue, Z. Spatiotemporal pattern of $\mathrm{PM}_{2.5}$ concentrations in mainland China and analysis of its influencing factors using geographically weighted regression. Sci. Rep. 2017, 7, 40607. [CrossRef] [PubMed]

77. McMillen, D.P. Geographically weighted regression: The analysis of spatially varying relationships. Am. J. Agric. Econ. 2004, 86, 554-556. [CrossRef]

78. Lu, B.; Charlton, M.; Brunsdon, C.; Harris, P. The minkowski approach for choosing the distance metric in geographically weighted regression. Int. J. Geogr. Inf. Sci. 2016, 30, 351-368. [CrossRef]

79. Wu, R.; Zhang, J.; Bao, Y.; Tong, S. Using a geographically weighted regression model to explore the influencing factors of $\mathrm{CO}_{2}$ emissions from energy consumption in the industrial sector. Polish J. Environ. Stud. 2016, 25, 2641-2651. [CrossRef]

80. Li, S.; Ye, X.; Lee, J.; Gong, J.; Qin, C. Spatiotemporal analysis of housing prices in China: A big data perspective. Appl. Spat. Anal. Policy 2016, 10, 1-13. [CrossRef]

81. Hu, X.; Wu, C.; Wang, J.; Qiu, R. Identification of spatial variation in road network and its driving patterns: Economy and population. Reg. Sci. Urban Econ. 2018, 71, 37-45. [CrossRef]

82. Jiansheng, W.U.; Zhang, P. The effect of urban landscape pattern on urban waterlogging. Acta Geogr. Sin. 2017, 72, 444-456.

83. Wang, C.; Du, S.; Wen, J.; Zhang, M.; Gu, H.; Shi, Y.; Xu, H. Analyzing explanatory factors of urban pluvial floods in Shanghai using geographically weighted regression. Stoch. Environ. Res. Risk Assess. 2017, 31, 1777-1790. [CrossRef]

84. Chakrovorty, S.; Haque, A. Land Market Receptiveness to Water-Logging: A Hedonic Pricing Approach Using GIS; Center for Research and Training (CRT): Dhaka, Bangladesh, 2017.

85. Kanga, S.; Singh, S.K. Mapping of Salt Affected and Waterlogged Areas Using Geospatial Technique. Int. J. Recent Innov. Trends Comput. Commun. 2017, 5, 1298-1305.

86. Majumder, A.K.; Hossain, M.S.; Al Nayeem, A. Assessment of people's perception on water logging in Chittagong City Corporation Area, Bangladesh. Assessment 2018, 5, 104-107.

87. Lei, W.; Li, C.C.; Ying, Q.; Xiao, C.; Wang, X.Y.; Li, X.Y.; Hu, L.Y.; Lu, L.; Le, Y.; Huang, H.B. China's urban expansion from 1990 to 2010 determined with satellite remote sensing. Chin. Sci. Bull. 2012, 57, 2802-2812.

88. Lu, D.; Song, K.; Zang, S.; Jia, M.; Du, J.; Ren, C. The effect of urban expansion on urban surface temperature in Shenyang, China: An analysis with landsat imagery. Environ. Model. Assess. 2015, 20, 197-210. [CrossRef]

89. Sen, B.I.; Wang, H.; Li, Z.; Tong, L.I.; Dong, L.; Han, R.D. Analysis of expansion of port cities in Hainan province based on impervious surface. J. Appl. Sci. 2017, 35, 346-354.

90. Chen, J.; Chang, K.T.; Karacsonyi, D.; Zhang, X. Comparing urban land expansion and its driving factors in Shenzhen and Dongguan, China. Habitat Int. 2014, 43, 61-71. [CrossRef] 
91. Wang, Y.; Wang, J.; Cui, H. The historic characterisitc and evolution of Guangzhou urban form. J. Qingdao Inst. Archit. Eng. 2002, 23, 32-37.

92. Zhao, M.; Xiong, K. Concept planning and the development stretegy of Guangzhou. Urban Plan. 2001, 25, 20.

93. Peng, J.; Liu, Y.; Shen, H.; Xie, P.; Xiaoxu, H.U.; Wang, Y. Using impervious surfaces to detect urban expansion in Beijing of China in 2000s. Chin. Geogr. Sci. 2016, 26, 229-243.

94. Committee, C. Review of Guangzhou Urban Planning Development; Guangdong Science \& Technology Press: Guangzhou, China, 2006.

95. Sim, T.; Wang, D.; Han, Z. Assessing the disaster resilience of megacities: The case of Hong Kong. Sustainability 2018, 10, 1137. [CrossRef] 